\title{
Members of Parliament are Minimally Accountable for Their Issue Stances (and They Know It)
}

\author{
CHRIS HANRETTY Royal Holloway, University of London, United Kingdom \\ JONATHAN MELLON University of Manchester, United Kingdom \\ PATRICK ENGLISH University of Exeter, United Kingdom
}

\begin{abstract}
7 or incumbents to be accountable for their issue stances, voters must sanction incumbents whose 4 positions are "out of step" with their own. We test the electoral accountability of British legislators 1 for their stance on Brexit. We find that there is very limited issue accountability. Individuals who disagreed with their representative's stance on Brexit were 3 percentage points less likely to vote for them. The aggregate consequences of these individual effects are limited. A one-standard-deviation increase in the proportion of constituents agreeing with their incumbent's Brexit stance is associated with an increase of 0.53 percentage points in incumbent vote share. These effects are one and a half times larger when the main challenger has a different Brexit stance to the incumbent. A follow-up survey of Members of Parliament (MPs) shows that MPs' estimates of the effects of congruence are similar in magnitude. Our findings suggest that issue accountability is conditional in nature and limited in magnitude even for an issue such as Brexit, which should be maximally amenable to such effects.
\end{abstract}

\section{INTRODUCTION}

$\mathbf{I}$ n June 2016, voters in the United Kingdom (UK) voted to leave the European Union (EU). The surprise outcome ran counter to opinion in parliament: 75\% of Members of Parliament (MPs) and $56 \%$ and $95 \%$ of Conservative and Labour MPs, respectively, had campaigned for the UK to remain in the EU. Ten months after the referendum, the new Prime Minister, Theresa May, called an early election in which her Conservative Party increased its vote share but lost seats. Some surprising Conservative losses in the 2017 general election occurred in areas that had voted to Remain, but where the incumbent Conservative MP had supported Leave. Defeats in Kensington and Canterbury - seats which had been Conservative since their creation-raised the question of whether Remain voters, regardless of whether they had become generally less likely to support the Conservatives, had punished Leave-supporting incumbents in particular (Chaffin 2017). More generally, the 2017 election raised the issue of whether incumbent MPs were held electorally accountable for their issue stances on Brexit.

The topic of legislators' electoral accountability for their issue stances is common enough in studies of the

Chris Hanretty (D), Professor of Politics, Department of Politics, International Relations and Philosophy, Royal Holloway, University of London, United Kingdom, chris.hanretty@rhul.ac.uk.

Jonathan Mellon (D), Senior Lecturer, Department of Politics, University of Manchester, United Kingdom, jonathan.mellon@ manchester.ac.uk.

Patrick English (D), Honorary Lecturer, Department of Politics, University of Exeter, United Kingdom, p.english@exeter.ac.uk.

Received: June 02, 2020; revised: February 28, 2021; accepted: May 13, 2021. First published online: July 08, 2021.
United States (US) Congress (Ansolabehere and Jones 2010; Canes-Wrone, Brady, and Cogan 2002; Nyhan et al. 2012). It has not, however, been a common topic in studies of other countries in general or British politics in particular. Strong party discipline means that most MPs' issue stances are the same as their party's. Even when party discipline does not apply, the views of legislators from the same party are often identical (Norton 2003). What within-party disagreement does exist is usually found on "matters of conscience": issues that parties agree to leave to the individual moral convictions of their MPs and that are not salient at general elections. Thus, while it is common to find explanations of voting behavior based on holding parties accountable for their competence or issue positions (Green and Hobolt 2008), the predominant assumption in British politics has been that although "the elector's support of a candidate may involve a calculus of policy choices ... it is a calculus to which the parliamentary candidate adds little beyond his adherence to party" (Butler and Stokes 1971, 512). Accordingly, there have been few studies on the accountability of individual MPs for their issue stances (as distinct from valence characteristics). The existing literature on electoral accountability for issue stances is almost entirely based on the experiences of incumbents in the US, a presidential system with weak political parties, which might therefore be regarded as a favorable environment for individual rather than party-based electoral accountability.

The postreferendum election, which combines a high salience issue with internal party division, offers an important opportunity to test whether individual MPs are sanctioned when they adopt positions that are "out of step" with their constituents. Our paper uses data from several waves of the British Election Study (BES) (Fieldhouse et al. 2018) to test whether 
Leave- (Remain-) supporting voters were less likely to vote for Remain- (Leave-) supporting MPs, controlling for respondents' prereferendum propensity to vote for the incumbent's party and other respondent and constituency characteristics. We are able to show that respondents were aware of incumbents' issue stances on Brexit and that a small negative effect comes from being out of step. However we find that the effect of being out of step is greater in contests where the nearest challenger is more "in step." Sanctioning was therefore greater (but still limited) where Leave-supporting incumbents faced a Remain-supporting challenger, and vice versa. We conclude that voters generally have the motive to sanction out of step incumbents but that only some voters have the opportunity to select better alternatives.

We then compare our findings on the actual electoral effects of being out of step with information on perceptions of the effects of being out of step. We presented a sample of MPs with vignettes of actual constituency contests and asked MPs to estimate how incumbents in the 2017 election would have performed if they had adopted a more (or less) congruent position. Investigating perceptions of electoral accountability is important because it is perceptions that give MPs reasons to act in particular ways and because MPs may still be incentivized to adopt congruent positions if they believe (falsely) that the effects of being out of step are large. We show, however, that MPs' beliefs in electoral sanctioning are consistent with the small effects we find in our analysis of the BES data. We interpret this to mean that legislators in the UK know they are only minimally accountable for their issue stances. We conclude by reflecting on the generalizability of our findings to other systems that use single-member districts and the normative implications of our findings for electoral system choice.

\section{LITERATURE}

This article is about accountability. Many thingsgovernments, parties, presidents - can be held accountable, but this article is about the accountability of individual legislators to voters. Voters can hold legislators accountable in different ways, but the most common accountability mechanism is sanctioning an incumbent by not voting for them.

Legislators can be held accountable on different grounds: either because they have done something that everyone regards as bad (or good), in which case we might talk about valence-based accountability, or because they have taken a position which is distant from voters' own position, in which case we talk about accountability for issue stances. The latter type of accountability is most easily investigated in single-member districts, with legislators' stances assessed relative to some summary measure of district opinion. Where issue stances are binary rather than continuous, we describe issue stances as being "congruent" or "in step" with constituency opinion if the legislator's stance is the same as the stance of the majority of their constituents.

Studies have shown that, generally, Congressional incumbents with extreme positions do worse than incumbents with moderate positions (Canes-Wrone, Minozzi, and Reveley 2011) and that American voters are more likely to vote for incumbents with whom they agree more (Ansolabehere and Jones 2010). Accountability for specific issue stances has been demonstrated across different issue areas: crime (Canes-Wrone, Minozzi, and Reveley 2011), trade (Jacobson 1996) and health care (Nyhan et al. 2012). This literature has identified necessary conditions for accountability for issue stances and moderators of the strength of issuebased sanctioning. For legislators to be held accountable for their issue stances, those stances must be out of step with district opinion, and information about the incumbent's issue stance must be widely available (Nyhan et al. 2012). Sanctioning is moderated by the salience of the issue (Bovitz and Carson 2006), the composition of the electorate (Griffin and Flavin 2007), the importance of the electoral contest (Rogers 2017), and whether the incumbent faces a challenger whose issue stances are more congruent than their own (Hollibaugh, Rothenberg, and Rulison 2013). Being out of step has substantively meaningful effects in Congressional contests for some important issues but does not have meaningful effects in elections to state legislatures. Nyhan et al. (2012, 859), for example, find that voting for the Affordable Care Act (ACA, generally unpopular when introduced) cost incumbents around 8 percentage points. Highton (2019) finds that ACA mattered, but that other issues-like financial regulation and repeal of the "Don't Ask Don't Tell" policy-had no substantively significant effects. Rogers $(2017,559)$, in a study of accountability of state legislators, finds that a onestandard-deviation increase in congruence improves incumbents' vote share by just 0.7 percentage points.

The problem with this literature is that it deals almost exclusively with the US. To our knowledge, only two published papers and a handful of analyses (in appendices to the Nuffield Election Studies) have directly assessed the accountability of individual legislators outside the US for their issue stances. Vivyan and Wagner (2012), in a study of rebelliousness in the UK Labour Party, find that the probability of voting for an incumbent Labour MP was greater among respondents who shared the MP's position on the Iraq War. This effect is both specific to one party (only two Conservative MPs rebelled over Iraq) and imprecisely estimated: the $95 \%$ confidence interval on the change in the probability of voting for the incumbent ran from -4 to +6 percentage points, with a point estimate of 1.2 percentage points. Curtice, Fisher, and Steed (2005) found (through a simple difference of means) an even smaller effect of rebellion of 0.2 percentage points. Pattie, Fieldhouse, and Johnston (1994) studied the electoral consequences of several free votes in the 1987-1992 parliament, using a factorial ANOVA, and found that MPs who supported two "populist" (and popular) measures-softening the poll tax and restoring the death penalty-gained 0.9 and 0.5 percentage points, respectively (no confidence intervals reported). As with Vivyan and Wagner (2012), this analysis is restricted to one party. Unlike Vivyan and Wagner (2012), it only operates as a test of issue accountability 
under the assumption that these votes were uniformly popular. Analyses of other issues likewise find few effects, concluding variously that "there is no evidence that capital punishment, immigration or any local issue had significant effects" (King and Butler 1966, 263), or (more relevant to our case) that there is no evidence that positions on European Monetary Union had any effect (Butler and Kavanagh 1997, 308).

There is almost no work on issue-based sanctioning outside the US, but there has been extensive research on valence-based sanctioning in systems with stronger parties, covering not only incumbency (Lee 2008; Smith 2013) and scandals (Banducci and Karp 1994; Basinger 2013; Eggers and Fisher 2011) but also signs of effort (Sulkin, Testa, and Usry 2015), independentmindedness (Campbell et al. 2019; Kam 2009, 103-29; Vivyan and Wagner 2012), and other positively valued attributes. This research has identified substantively meaningful effects in both the US and the UK. These are plotted in Figure 1, together with effects from studies of issue-based accountability.

This literature asks whether voters do in fact hold incumbents accountable. However, accountability can also be secured if legislators (falsely) believe that they will be held accountable. There are reasons to think that MPs may believe just this. In social psychology, the "spotlight effect" (Gilovich, Medvec, and Savitsky 2000) refers to the tendency to overestimate the salience of our own actions, relative to how they are perceived by others. It is reasonable to believe that politicians (individuals who score highly on measures of narcissism and low on measures of humility: Blais, Pruysers, and Chen 2019) are also subject to this "egocentric bias," and believe (falsely) that many of their constituents are aware of, and responsive to, their votes. Like many cognitive biases (Chen, Shechter, and Chaiken 1996), the spotlight effect may be counteracted by the (electoral) incentive to form accurate impressions of voters' beliefs, but studies of politicians' beliefs have shown that politicians can hold persistent incorrect beliefs about voters, who they regard as (variously) more conservative than then really are (Broockman and Skovron 2018), more in line with their own opinion than they really are, and more like groups they meet regularly (Pereira 2020). To our knowledge, only one paper (Skovron 2018) has directly examined politicians' beliefs about accountability, but it does so by examining politicians' beliefs about antecedent processes such as differential turnout rather than directly asking politicians about the electoral effects of particular stances. There is therefore a gap in the literature for studies of politicians that directly assess politicians' beliefs about the electoral penalties of issue stances in a way that minimizes politicians' desire to present their own actions as consequential.

\section{CONTEXT}

We assume a working knowledge of the 2016 Brexit referendum and the 2017 general election (an overview is provided in Cowley and Kavanagh (2018). Instead of providing a chronological overview, we identify six basic facts about the referendum and the election that make it appropriate to study issue accountability in this context.

First, MPs adopted positions on the referendum that were widely reported. The informal referendum campaign began on February 19, 2016, when then-Prime Minister David Cameron returned from a European Council with "a new settlement" for the UK within the EU. ${ }^{1}$ Within a week, $85 \%$ of MPs had "declared" for either Leave or Remain, either through individual statements or through the two campaign organizations, Vote Leave and Britain Stronger in Europe. The positions of individual MPs were reported on the BBC website and in the national and local press. ${ }^{2}$ Although this does not guarantee that constituents were aware of MPs' positions, it does show that this information was widely available. One necessary condition for issue accountability - "the dissemination of information about the [issue stance] itself" (Nyhan et al. 2012, 849) -is therefore met.

Second, MPs' positions revealed significant withinparty division in the two largest parties. While the smaller parties either uniformly supported leaving the EU (UK Independence Party, UKIP) or opposed it (Liberal Democrats, Scottish National Party, Plaid Cymru, The Green Party), Labour and Conservative parliamentarians campaigned for both sides. While a majority (56\%) of Conservative MPs - including David Cameron-campaigned for Remain, the Conservative party as an organization was formally neutral in the referendum (Shipman 2016, 88). Labour's position was less equivocal, but enough Labour MPs campaigned for Leave (10 of 228) to test of whether these MPs benefited from their position. This within-party division is a further necessary condition for identifying individual issue accountability: if there is no within-party division, it is impossible to distinguish the effects of an individual MPs' position from the effects of their party affiliation. For this reason, we can only study the individual issue accountability of Labour and Conservative MPs, as these were the only parties that were divided on the issue of Brexit.

Third, because of the result, many MPs were revealed to have adopted out-of-step positions. This was particularly true for Labour MPs. Because the referendum was counted in local authority areas, rather than Westminster constituencies, there are no official records of how each constituency voted, but estimates (Hanretty 2017) suggest that around half of MPs were out of step with their constituents on Brexit. This figure was higher for Labour MPs (around 60\%) and Remainsupporting MPs (58\%) than it was for Conservative MPs $(46 \%)$ and Leave-supporting MPs $(21 \%))^{3}$ Although

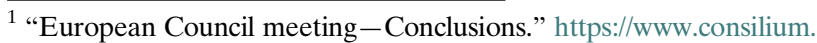
europa.eu/media/21787/0216-euco-conclusions.pdf.

${ }^{2}$ See https://www.bbc.co.uk/news/uk-politics-eu-referendum-35616946, https://www.mirror.co.uk/news/uk-news/how-mp-vote-eu-referendum9187679, or http:/home.bt.com/news/uk-news/how-mps-voted-in-theeu-referendum-11364110245462.

${ }^{3}$ These figures are based on MPs who declared a position prior to the referendum. They exclude a number of parliamentary office holders (Speakers and Deputy Speakers) as well as MPs who did not declare a position.
} 


\section{FIGURE 1. Selected Effects of Valence- and Issue-Based Accountability}

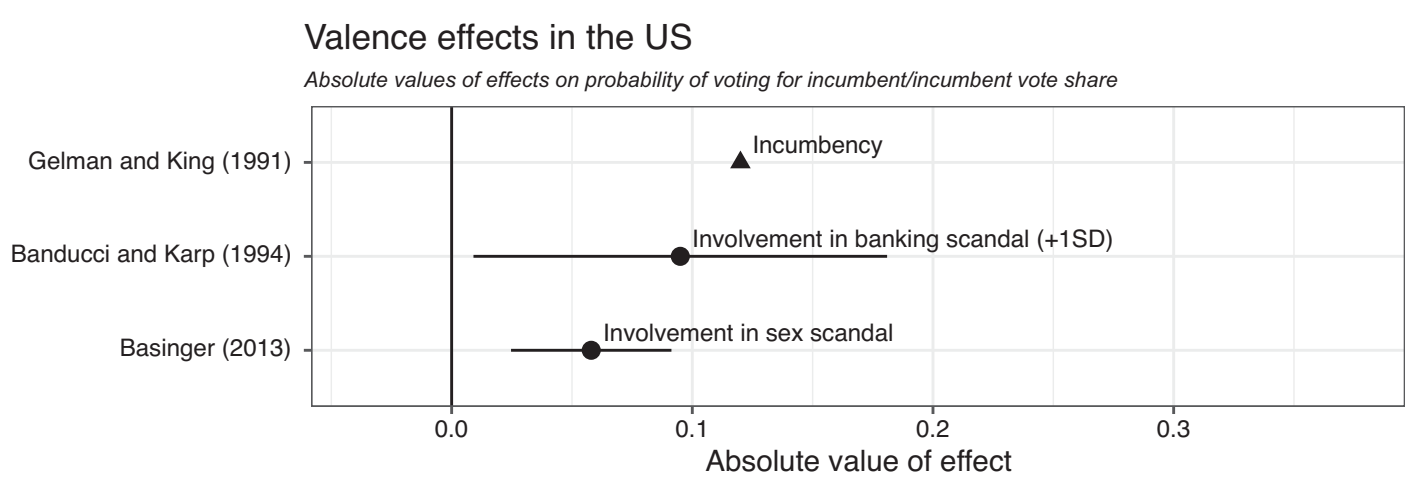

Positional effects in the US

Absolute values of effects on probability of voting for incumbent/incumbent vote share

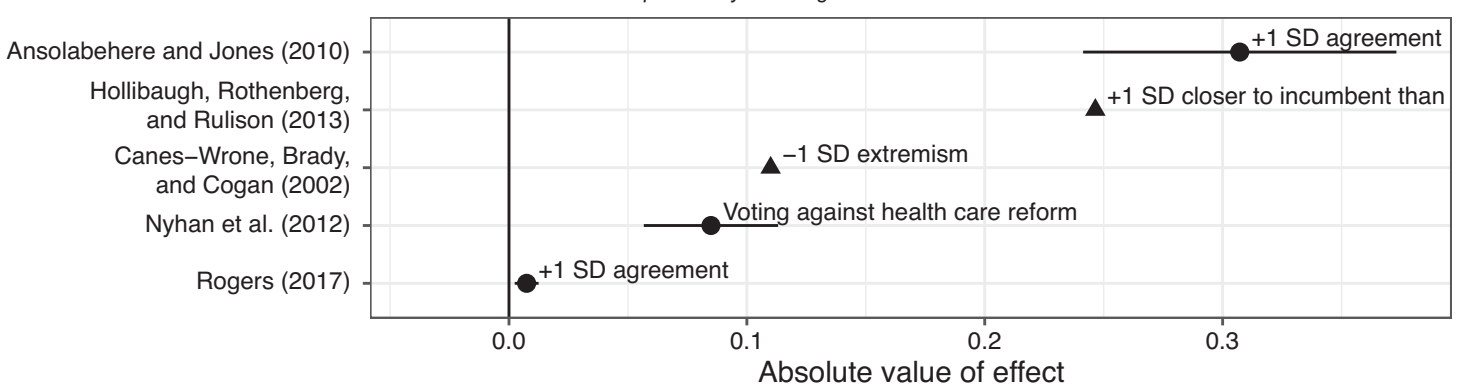

Valence effects, UK

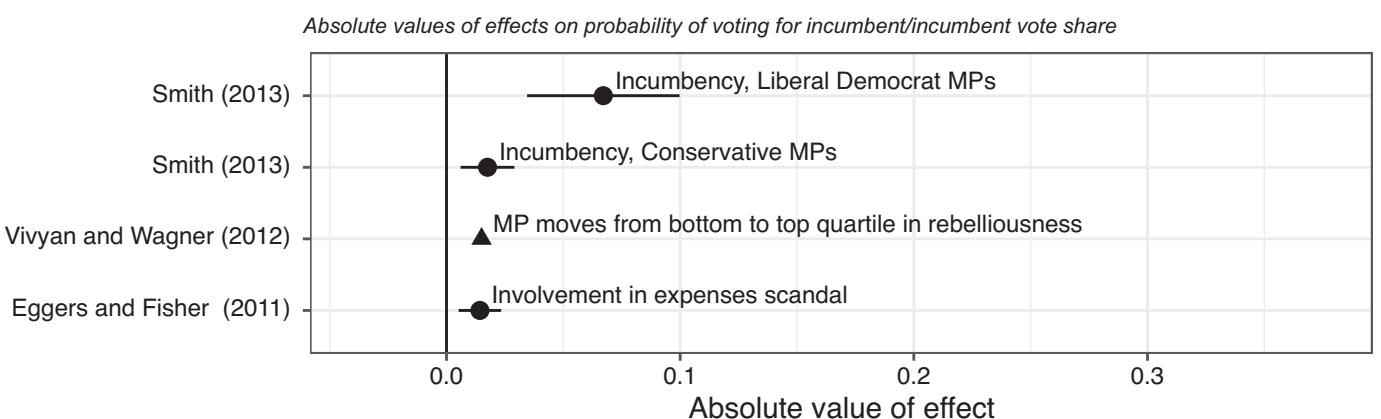

Positional effects, UK + Switzerland

Absolute values of effects on probability of voting for incumbent/incumbent re-election probability

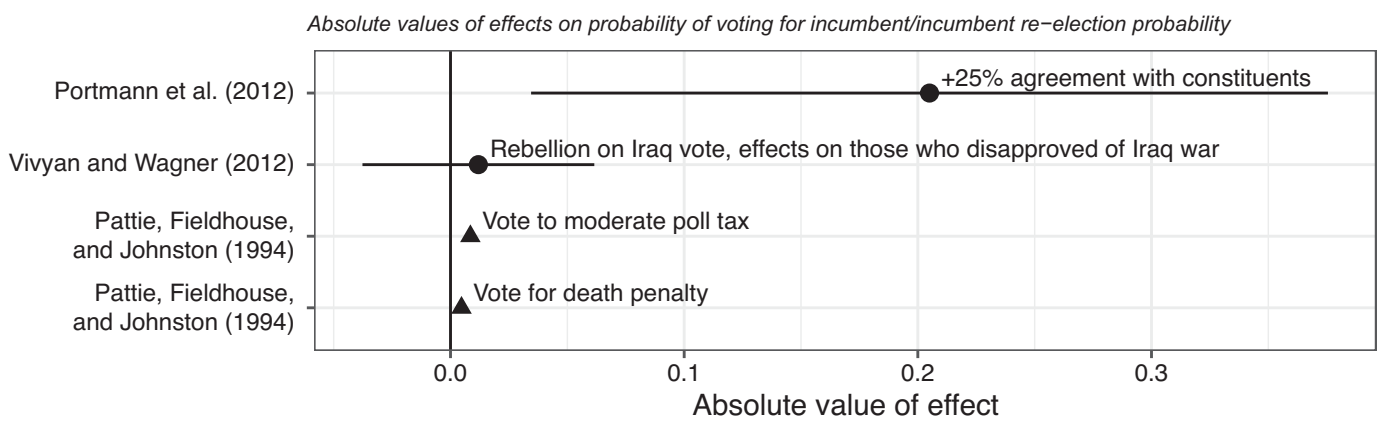

Note: Estimates with no reported confidence intervals are plotted with a triangle.

Conservative MPs were more in step with their constituents, the degree of congruence for both parties was low.

Fourth, the subsequent 2017 election was about Brexit, both in its inception and in how voters approached it. The next general election after 2015 would ordinarily have taken place in 2020, but Theresa May-Cameron's replacement as Prime Ministerdecided to initiate an early election. Her rationale for doing so was that other parties in Parliament were "[jeopardizing] the work we must do to prepare for 


\section{FIGURE 2. Change in Incumbent Vote Shares as a Function of Leave Vote Share in Each Constituency}

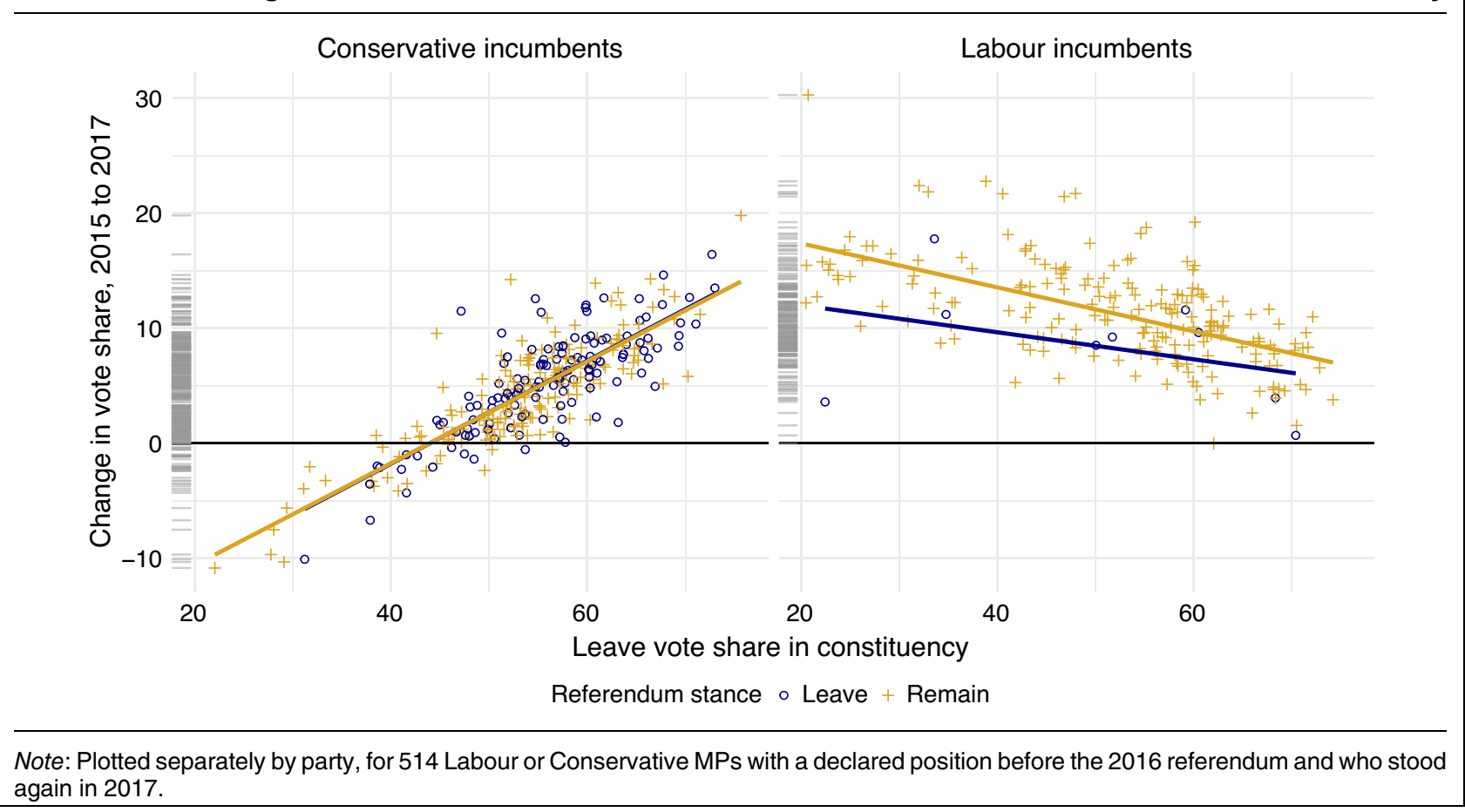

Brexit at home and ... [weakening] the government's negotiating position in Europe." A Although they might not have accepted this analysis, voters agreed that Brexit was the most important issue in the election: $36 \%$ of respondents to the postelection BES face-to-face survey cited Brexit or Europe as the most important issue facing the country, much higher than the percentage that identified health or the National Health Service (11\%), terrorism $(6 \%)$, or the economy $(10 \%))^{5}$ This is extremely unusual for an "episodic" issue like Brexit. ${ }^{6}$ The issue of Brexit was therefore highly significant.

Fifth, there were significant links between the Leave share in each constituency and parties' shares of the vote. Figure 2 shows changes in the vote shares of Conservative (left panel) and Labour (right panel) incumbents as a function of the Leave share in each constituency, with separate symbols and trend lines for MPs who campaigned for Remain and for Leave.

\footnotetext{
4 “Theresa May's General Election Statement in Full." BBC News Online, https://www.bbc.co.uk/news/uk-politics-39630009.

${ }^{5}$ These percentages are based on regular expression matching the freetext entries reported in the British Election Study face-to-face survey. The case-insensitive search terms were "Brexit|Europ $\mid<E U \backslash>$," "health|NHS," "terror|isis," and "econ|job|wage|employ," respectively. ${ }^{6}$ An examination of other episodic issues in British political history shows that although the poll tax was for a brief point (February to June 1990) the most important issue in British politics, but it had ceased to be the most important issue by the time of the 1992 election: on this, see https://www.ipsos.com/ipsos-mori/en-uk/importantissues-facing-britain. War in Iraq was, under the heading of national defense, the most important issue in February and March of 2003, but by the 2005 election it had become the fifth most important issue after immigration, crime, health, and the economy (Johns 2010, 149). COVID-19 has since become another unusual "episodic" issue.
}

Conservative incumbents increased their vote share more in constituencies that had voted more heavily to Leave. The pattern for Labour was the reverse. Analysis of individual-level evidence also shows significant switching according to Brexit position (Mellon et al. 2018). If the issue of Brexit was salient enough to have affected party vote shares, it is plausible that it was salient enough to have affected individual candidates' vote shares.

Sixth, the UK is a case where it makes most sense to study issue accountability. It is in single-member districts where the idea of legislators' individual electoral accountability for issue stances is most easily understood. Dyadic representation - the degree to which legislators' policy positions reflect their constituents' policy preferences - is premised on a simple relationship between a legislator and their constituency, understood as a single principal. Where district magnitude is greater than one, it may not make sense to conceptualize the constituency as a single principal but rather as multiple principals defined by party identification, or possibly some other characteristic (Golder and Stramski 2010). Given the difficulties inherent in specifying these groups, testing the electoral accountability of legislators for their issue stances becomes very difficult outside the set of countries that use single-member districts and in which we can talk of a one-to-one congruence relationship. Because rates of legislative unity in these democracies (principally the UK, the US, Canada, Australia, France, and India) are - with the exception of the US - generally high (Depauw and Martin 2009; Kam 2009, 8), it is important to use occasions where there is within-party disagreement to test for the influence of individual legislators' stances, as we do here. 


\section{THE UNCONDITIONAL EFFECTS OF CONGRUENCE}

The data for this analysis come from the 2014-2021 BES Internet Panel. There have been 20 waves of the panel; the first wave took place during FebruaryMarch 2014, and the most recent in June 2020. We rely most heavily on data from waves seven (AprilMay 2016, before the referendum), and 13 (June 2017, after the general election). We also use preelection waves 11 and 12 for data concerning perceptions of MPs' stances on Brexit. We augment data from the BES with information on MPs' prereferendum issue stances (taken from the BBC) and information on the characteristics of the different constituencies (taken from several different sources). The multiple waves of the BES allow us to control for characteristics of respondents measured before their MP had adopted a position on the referendum. Our analysis is restricted to participants in the postelection wave who said whether and how they voted and who could be associated with a constituency. We imputed missing survey data using Amelia (Honaker, King, and Blackwell 2011).

The scope of our analysis is restricted to respondents from constituencies represented by a Conservative or Labour incumbent who was in office at the start of the referendum campaign and who stood for reelection. We restrict our analysis to Conservative and Labour incumbents because these are the only parties that were internally divided on Brexit and for whom we can distinguish between individual and party effects. We restrict our analysis to incumbents who were in office at the start of the referendum campaign because it is not clear whether information on the issue stances of the seven Labour or Conservative MPs who took office after the beginning of the campaign $^{7}$ was widely publicized. Finally, we restrict our analysis to MPs seeking reelection. ${ }^{8}$ We are left with information from 25,189 respondents. Of these, $46 \%$ voted Leave in the referendum, $44 \%$ Remain, and $9 \%$ did not vote.

The dependent variable in our analysis is whether the respondent voted for the incumbent. We create two versions of this variable. One version has a value of one when the respondent voted for the incumbent and a value of zero in all other cases, including both cases where the respondent voted for a challenger and cases where the respondent did not vote at all (mean = 0.45 ). The other version excludes cases where the respondent did not vote $($ mean $=0.51)$. Because it is more closely connected to the size of MPs' majorities, we privilege estimates based on analyses excluding nonvoters, but our substantive conclusions do not

\footnotetext{
${ }^{7}$ Rosena Allin-Khan, Robert Courts, Sarah Caroline Johnson, Gareth Snell, Trudy Harrison, Tracy Brabin, and Gill Furniss.

${ }^{8}$ In table S12 we show that there is no significant association between congruence and retirement decisions when controlling for age. This is different from cases of scandal (Eggers and Fisher 2011).
}

depend on which version of the dependent variable we use.

The independent variable in our analysis is whether the respondent's MP adopted the same position on Brexit as the respondent. This variable has a value of one when the respondent and MP both supported Leave or both supported Remain and a value of zero in all other cases, including cases where either the MP or the respondent adopted no position or did not vote $($ mean $=0.46)$.

The control variables in our analysis are of three kinds: control variables required because of the nature of the independent variable, control variables required because of the potential for constituency characteristics to confound a relationship between congruence and outcomes, and control variables that it is desirable to include to increase the efficiency of our estimates and guard against the possibility of nonrandom sample selection.

The first set of control variables includes controls for the incumbent's referendum position and the respondent's referendum vote. These control variables are implied by how our key independent variable is constructed. Because the value of congruence depends on the values of two other terms, it functions like an interaction term. When models use interaction terms, it is also necessary to include the constituent terms of the interaction: failure to include constituent terms usually leads to biased estimates (Brambor, Clark, and Golder 2005). Bias might otherwise arise if Leave-supporting MPs generally did better than Remain-supporting MPs across all classes of voter or if Leave-supporting respondents were generally less likely to support incumbents across all classes of incumbents.

The second set of control variables includes constituency-level variables that might affect both the likelihood that the MP adopts a particular position and their vote share. The prior strength of UKIP is just such a confound. MPs faced with a strong challenge from UKIP adopted more Euroskeptic positions to deter future UKIP challenges and retain Euroskeptic voters (Heppell, Crines, and Jeffery 2017, 769). Prior UKIP strength was also positively associated with changes in incumbent vote shares because the party collapsed after the EU referendum had been won.

It is never possible to identify all such confounding variables. We base our selection of control variables on work that has modeled aggregate-level outcomes at the 2017 election (Heath and Goodwin 2017, 355), work that has looked at the medium-term economic causes of Brexit (Colantone and Stanig 2018), and general work on incumbents' fortunes (Martin 2016; Smith 2013). From the 2011 census (following Heath and Goodwin 2017), we take information on the proportion of the constituency population aged 18-29, the proportion with a university degree, the proportion of ethnic minority residents, and the proportion of unemployed residents. From Colantone and Stanig (2018) we take information on exposure to Chinese import shocks, but remapped to Westminster 
constituencies. We also include information on the incumbent's tenure (one, two, or more terms); whether the incumbent was in the (shadow) cabinet; and the 2015 share of the vote for the Conservatives, Labour, and UKIP. Finally, we include prereferendum estimates of constituency-level support for exiting the EU. These estimates were produced using multilevel regression and poststratification, using opinion poll data gathered between 2010 and 2014 (Hanretty, Lauderdale, and Vivyan 2018). ${ }^{9}$

We do not include as constituency-level controls whether UKIP or The Green Party fielded candidates in each seat. These decisions were made after incumbents had adopted their referendum positions. These variables are therefore "posttreatment" variables: their inclusion in a regression would mean that we would not-even in principle-be estimating the total causal effect of MPs' issue positions on their vote share.

The third set of controls are controls for individuals' characteristics. Strictly speaking, we do not need to control for individual level measures to recover the causal effect of congruence, because there is no causal pathway from "characteristics of particular respondents" to "MPs' decisions." However, the inclusion of additional controls can increase the precision of our estimates, and this allows for the possibility that the sample is not a random sample of the population. For that reason, we include the respondent's propensity to vote (PTV) for the main UK-wide parties (Conservatives, Labour, Liberal Democrats, UKIP, and The Green Party). These PTV variables were measured in the seventh BES wave, completed before the referendum (fieldwork dates: April 12-May 4, 2016). The PTV variables offer a finegrained characterization of the respondent's political propensities.

To recover the effects of MPs' stances, we estimate a multilevel logistic regression model using different sets of these covariates. We use a multilevel model because respondents are clustered into constituencies. We use a logistic regression model because our outcome is dichotomous. We use a regression model rather than matching because even after coarsening (Iacus, King, and Porro 2012) the number of matches is very much smaller than the number of units available for the regression, reducing the efficiency of our estimates.

Formally, our model is as follows: the probability of individual $i$ in constituency $j$ voting for the incumbent $\left(y_{i j}=1\right)$ is a function of a global intercept $(\alpha)$, constituency-specific random intercepts $\left(\mu_{j}\right)$, MP position, respondent position, congruence, constituency covariates gathered in $\mathbf{X}_{\mathbf{j}}$, individual covariates gathered in $\mathbf{Z}_{\mathbf{i}}$, and an indicator variable that has value 1 if the incumbent was a Labour incumbent. Specifically,

\footnotetext{
${ }^{9}$ We use prereferendum campaign estimates rather than postreferendum estimates because the referendum outcome in each area might have been influenced by MPs' positions and may therefore be posttreatment.
}

$$
\begin{aligned}
& \operatorname{logit}\left(\operatorname{Pr}\left(y_{i j}=1\right)\right)=\alpha+\mu_{j} \\
& +\beta_{1} \cdot \text { MP supported Remain }{ }_{j} \\
& +\beta_{2} \cdot \mathrm{MP} \text { undeclared }{ }_{j} \\
& +\beta_{3} \cdot \mathrm{R} \text { supported Leave in } 2016_{i} \\
& +\beta_{4} \cdot \mathrm{R} \text { did not vote in } 2016_{i} \\
& +\beta_{5} \cdot \mathrm{R} \text { and MP congruent }{ }_{i j} \\
& +\mathrm{X}_{\mathbf{j}} \beta_{6.28} \\
& +\mathbf{Z}_{\mathbf{i}} \beta_{29.51} \\
& +\mathbf{X}_{\mathbf{j}} \beta_{52 . .57} \cdot \text { Labour incumbent }_{j} \\
& +\mathbf{Z}_{\mathbf{i}} \beta_{58.63} \cdot \text { Labour incumbent }_{j} \\
& +\mathbf{X}_{\mathbf{j}} \beta_{64.86} \cdot \mathrm{R}_{\text {supported Leave }} \\
& +\mathbf{Z}_{\mathbf{i}} \beta_{87 . .92} \cdot \mathrm{R} \text { supported Leave }{ }_{i} \\
& +\mathbf{X}_{\mathbf{j}} \beta_{\mathbf{9 3 . 1 1 5}} \cdot \mathrm{R} \text { did not vote in } 2016_{i} \\
& \mathrm{Z}_{\mathbf{i}} \beta_{\mathbf{1 1 6 . 1 2 1}} \cdot \mathrm{R} \text { did not vote in } 2016_{i} \text {. }
\end{aligned}
$$

This specification allows for Labour incumbents to do better in certain types of constituencies but not others and among certain types of voters but not others. It also allows for the link between respondent and constituency characteristics to vary according to 2016 referendum behavior. This is necessary: the link between propensity to vote Conservative ought to be positive for Conservative incumbents and negative for Labour incumbents. The same is true, less obviously, for constituency characteristics.

By subsetting the data and removing interaction terms, the model can be estimated on Leave or Remain voters only, or on respondents in Labour- or Conservative-held seats only, or on some combination of the two. When subsetting to Remain voters, we report the effect of "MP supported Remain," rather than " $R$ and MP congruent" (which we drop). When subsetting to Leave voters, we use "MP supported Leave" instead of "MP supported Remain." In all other cases, we report the effect of " $R$ and MP congruent."

Given the large number of coefficients in each model and the difficulties of comparing logistic regression coefficients estimated across different data subsets (Breen, Karlson, and Holm 2018), we present average marginal effects (AMEs) of the relevant variables. Figure 3 shows AMEs for different combinations of incumbent party, voter type, and dependent variable. Estimates plotted with a circle show the results from a model estimated on all respondents; estimates plotted with a triangle show the results from a model estimated on 2017 voters only. The figure shows that the effects of congruence on the probability that an individual respondent will vote for the incumbent range from -0.1 percentage points (the effect of congruence on Remain-voting respondents in Conservative-held seats) to 4.9 percentage points (the effect on Remain voters in Conservative-held seats). Our best estimate of a single, unconditional congruence effect on voters is 2.3 percentage points $(95 \%$ CI: $1.1-3.55$ percentage points).

These are individual effects. The aggregate consequences of these individual effects are necessarily 


\section{FIGURE 3. AMEs from a Model of Unconditional Issue Accountability, with Separate Estimates by Voter Type and Seat Type}

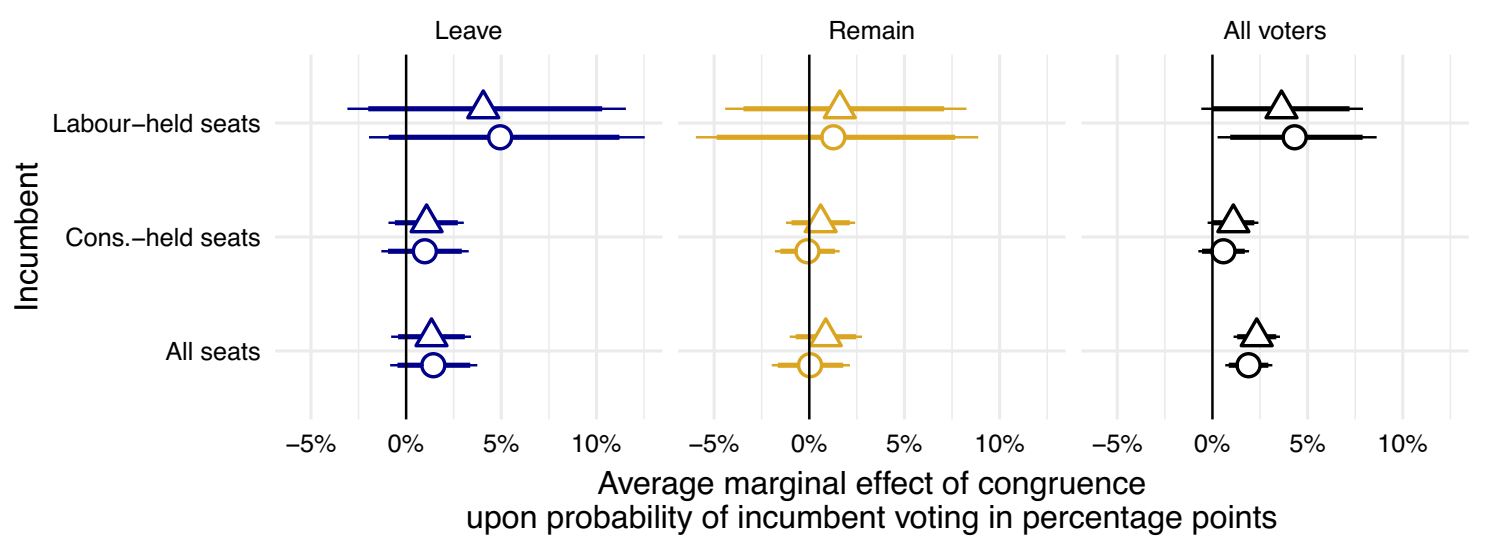

Model estimated on ... $\bigcirc$ All repondents $\triangle$ Voters only

Note: Thin bars show 95\% credible intervals; thick bars 90\% credible intervals. Estimates derive from tables S2-S4.

smaller, as any increases in aggregate vote share that result from changing an MP's position to match Leavers (for example) are partially cancelled out by losses among Remainers. The size of the aggregate consequences will therefore depend on the imbalance in constituency opinion. If we measure constituency-level congruence as the proportion of the constituency that supports the MP's position, then the standard deviation of this constituency-level measure is 11.3 percentage points. A one-standard-deviation increase in congruence would occur if a Remain-supporting MP switched to Leave in a constituency where $(50+11.3 / 2=)$ $55.7 \%$ of citizens voted Leave. On the basis of a single pooled congruence effect, then the aggregate consequences of such a switch would be around 0.53 percentage points $(95 \% \mathrm{CI}:[0.25,0.81]){ }^{10}$

Are effect sizes of 2.3 percentage points at the individual level or 0.53 percentage points at the aggregate level large or small? We draw four comparisons. First, the effects are small relative to the effects of other covariates: the coefficient on congruence is one tenth the size of the coefficient on propensity to vote. Second, the effects are small relative to benchmarks for the minimal important distance: $0.56 \%$ is less than the the "fourth percentile of margin of victory" threshold used by Fortunato and Monroe (2018) (2\% in the case of the

\footnotetext{
${ }^{10}$ Let $L$ be the proportion of Leavers in a constituency, and $R$ the proportion of Remainers. Then, if $b$ is the baseline probability of supporting some candidate and $\delta$ is the change in probability associated with congruence, then the vote share when the MP supports Leave $\left(Y_{L}\right)$ is equal to $Y_{L}=(b+\delta) L+(b-\delta) R$, whereas the vote share if the MP supports Remain $\left(Y_{R}\right)$ is equal to $Y_{R}=(b-\delta) L+(b+\delta) R$. The difference in vote share associated with a switch from Remain to Leave is therefore $(b+\delta) L+(b-\delta) R-(b-\delta) L-(b+\delta) R$, which simplifies to $2 \delta L-2 \delta R$. If we substitute in values from the worked example above, where $55.7 \%$ of the MP's constituents favored Leave, and she switched from Remain to Leave, then we can solve $x=2 \cdot 0.025 \cdot 0.557-2 \cdot 0.025 \cdot(1-0.557)$ to find that $x=0.0057$. This calculation ignores variation in constituency sizes and turnout.
}

US House; $0.8 \%$ in the UK). Third, the effects are also small relative to the effects of congruence in the US House on important issues: Nyhan et al.'s (2012) estimates of the effects of voting against the (then generally unpopular) Affordable Care Act are 13 times larger. The effects are comparable to those of roll-call congruence in US state legislatures given a similar onestandard-deviation shift (Rogers 2017). Finally, the aggregate consequences are substantially smaller than the estimated effect of being implicated in the 2007 parliamentary expenses scandal (Eggers and Fisher 2011). This illustrates well the potential differences in the magnitudes of valence effects (which operate on all voters) and congruence effects (which operate only on the congruent).

\section{THE CONDITIONAL EFFECTS OF CONGRUENCE}

The previous section estimated the effect of the incumbent's position on Brexit matching the respondent's own position on the probability of the respondent voting for an incumbent. The effect we estimated was unconditional: whether the incumbent's position was congruent was an equally strong reason for (not) voting for the incumbent across all different contexts. There are, however, good reasons to think that the effect of being out of step varies across different electoral contexts. In particular, voters may be more likely to vote against an out-of-step incumbent if there is a relevant challenger who is more in step than the incumbent. Remain voters may be more likely to vote against a Leave-supporting MP if there is a relevant challenger who supports Remain, but not if the nearest challenger also supports Leave.

Hollibaugh, Rothenberg, and Rulison (2013) demonstrated this kind of conditional accountability in Congressional elections. They argued that the best 


\section{FIGURE 4. AMEs from a Model of Conditional Issue Accountability, with Separate Estimates by Voter Type and Seat Type}
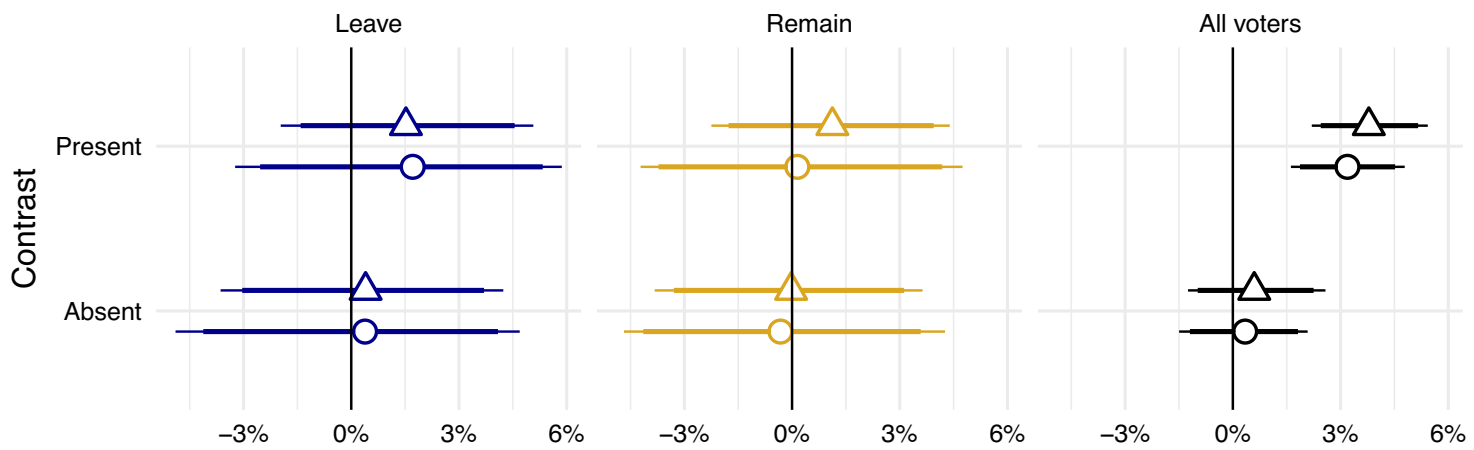

Average marginal effect of congruence

upon probability of incumbent voting in percentage points

Model estimated on ... $\bigcirc$ All repondents $\triangle$ Voters only

Note: These estimates derive from table S5.

model of incumbent support is based not on the distance between the respondent and the incumbent but on how much closer the incumbent is to the respondent than the challenger. This means that holding an incumbent to account can also involve selecting a better replacement and that the unconditional effects estimated in the previous section may underestimate the effects of issue stances in certain types of contest.

To test conditional issue accountability, we collected information on the prereferendum positions of the parliamentary candidates selected by the secondplaced party in 2015 ("challengers"). Challengers were drawn from several different parties but predominantly from Labour (198 candidates), the Conservative Party (155), and UKIP (105). ${ }^{11}$ We began by examining candidates' social media activity prior to the referendum. Where candidates had made clear statements in favor of Leave or Remain, we coded their position accordingly. We contacted (by email) candidates who made no clear statement or had no social media profile. We were able to identify referendum positions for 336 of 524 challengers. Only in the Conservative party was there within-party variation, with a majority of Conservative challengers (67 of 87 with identifiable positions) favoring Leave. All remaining parties' challengers supported either Remaining (Labour, Liberal Democrats, Scottish National Party, and Plaid Cymru) or Leaving (UKIP).

Using the information on challenger positions, we distinguish between two types of constituency contests: contests where the challenger had a different position (the incumbent supported Leave and the challenger

\footnotetext{
${ }^{11}$ Although UKIP were the best-placed challengers based on the 2015 results, the party suffered a collapse in support following the Brexit referendum. Absent constituency polling capable of indicating the second-placed party prior to the 2017 election, we see no principled alternative to taking the positions of the UKIP candidates where the party placed second in 2015 .
}

Remain, or vice versa) and contests where the challenger and incumbent had the same position.

We therefore reestimate the model described in the previous section, adding an interaction between the type of contest and the measure of congruence. Because this model has the character of a three-way interaction (respondent position $\times$ incumbent position $\times$ type of contest), we once again eschew tables of coefficients and present the AMEs of congruence evaluated in no-contrast and contrasting contests. These are shown in Figure 4. As before, we give estimates from models estimated on Leave voters, Remain voters, and all respondents and according to whether the respondent voted in 2017.

The effects of congruence in contests where the nearest challenger has the same position on Brexit are all very close to zero, and one has the wrong sign. The effects of congruence in contests where the nearest challenger has a different position are larger, but they are only significantly different from zero when we pool together both Leave and Remain voters. In these models, the effect of congruence is around 4\% - regardless of whether we include nonvoters in the sample-and is relatively precisely estimated. This is more than one and a half times the size of the unconditional effect. At the aggregate level, a onestandard-deviation change in congruence would yield an increase in vote share of 0.86 ,with $95 \%$ CI: $[0.5,1.24] .{ }^{12}$

A model interacting congruence with the type of contest was suggested by theory and delivers very different AMEs. This more complicated model also fits the data better: the value of the leave-one-out criterion (LOOIC) is lower (better) for the conditional model than for the unconditional model $(20,617.6$ to $20,625.5$, with a standard error on the difference of 4 units).

\footnotetext{
12 This calculation uses the effect on voters (rather than all respondents) and the algebra in footnote 10.
} 
These results are not the result of other constituency characteristics associated with both contrasting incumbent/challenger positions and the strength of incumbent sanctioning. Previous research has argued that dyadic representation should be stronger in more educated areas and more marginal seats (Griffin 2006; Lloren and Wüest 2016). Yet areas where the nearest challenger had a different stance on Brexit tended to have lower levels of education $(15.6 \%$ of the population have a university degree compared with $18.0 \%$ in seats without contrast) and higher majorities (average majority of 25.9 percentage points compared with 24.0 percentage points in noncontrasting races), which suggests that these constituency characteristics cannot account for the stronger effect we see. Races where the nearest challenger had a different position on Brexit did have higher UKIP performance in the past (average vote share of 14.9 percentage points compared with 13.4), but we do not see this as a rival interpretation: UKIP provided some of the contrast we see.

Using these conditional effects, we can work out the implications of congruence for the 2017 election. Thirty-seven of the 524 MPs considered here lost their seat in the election. Of these, 16 were also out of step with their constituency. Seven of these $16 \mathrm{MPs}$, because they faced a challenger who had a contrasting position, could reliably have improved their vote share by switching. In four cases, the increase in vote share might plausibly have exceeded the challenger's margin of victory. In Kensington (69\% Remain), Victoria Borwick would have gained just under 3 percentage points by switching from Leave to Remain - greater than the very small majority her Labour challenger won (0.05\%). In Canterbury (55\% Remain), Julian Brazier would have won 0.7 percentage points, again greater than the majority of his Labour challenger $(0.33 \%)$. Had these two Conservative MPs switched, the Conservative party would still have lost its majority but would have been less reliant on legislative support from the Democratic Unionist Party. Conversely, two Labour MPs could have retained their seats had they switched. Rob Flello, MP for Stoke-on-Trent South ( $71 \%$ Leave) could have secured 3.2 percentage points more by switching, exceeding his (Conservative) opponent's majority of 1.6 percentage points. Alan Meale (Mansfield, 71\% Leave) could also have beaten Conservative candidate Ben Bradley with a similarly sized swing.

\section{OBJECTIONS AND LIMITATIONS}

In presenting earlier versions of this work, we encountered two objections, both of which concern the causal pathway between MPs' stances and respondents' votes. The first objection runs as follows: for MPs to be held accountable, voters have to know how MPs campaigned during the referendum. However, past research has shown that only a small minority of people know the name of their own MP (Hansard Society 2013; cf. Cowley 2014). It is therefore implausible that any incumbent sanctioning should exist given widespread ignorance.

We respond to this objection by showing that there was an association between MPs' stances and survey respondents' perceptions of their MP's stance. Waves 11 and 12 of the BES (preelection waves fielded between April and June 2017) asked respondents about their perceptions of their local MP's stance on Brexit, on a scale from 1 to 5 , where 1 means the MP "strongly opposes" Brexit and 5 means the MP "strongly supports" Brexit (mean of 3.14; SD =1.3). We model respondent perceptions using the same formula as in Equation 1,13 except that we drop the " $\mathrm{R}$ and MP congruent" term. For ease of interpretation, we use a multilevel linear model, despite the discrete character of the responses.

Because our model is a linear model, we plot model coefficients rather than AMEs. We focus on the effects of MP position (our key independent variable) as well as two important control variables: the incumbent's party-because respondents may project party positions onto MPs - and the respondent's own position because respondents may project their own position on to incumbents (Wilson and Gronke 2000). The values of these coefficients are shown in Figure 5 for models estimated separately on respondents in Conservativeheld seats, Labour-held seats, and all seats.

The strongest association with perceived Brexit stance is party: Labour incumbents are perceived as much more hostile to Brexit than Conservative incumbents (the reference category). However, this association is only very slightly stronger than the association with MPs' actual issue stance. On a 1-5 scale, MPs who campaigned for Remain are 0.6 points $(0.48$ standard deviations) more hostile to Brexit. MPs who adopted no position are more likely to be perceived as hostile to Brexit than MPs who campaigned for Leave. Surprisingly, voters do not project their own views onto their incumbent.

The fact that there is a substantively meaningful and statistically significant association between MPs' actual positions and how those positions were perceived does not mean voters were well informed, in some absolute sense, about MPs' positions. Just over half of respondents $(52 \%)$ gave the correct answer (scores of 4 or 5 for MPs who had campaigned for Leave, scores of 1 or 2 for MPs who had campaigned for Remain, scores of 3 for MPs who were undeclared). These findings do, however, allow us to show that the incumbent sanctioning we have identified can operate through changed perceptions on the part of voters. When we model incumbent voting using perceived congruence rather than actual congruence, we obtain standardized effect sizes that are twice as large (tables S7-S9; Figure S1). Had voters had perfect knowledge of MPs' positions, issue accountability would have been greater.

The second common objection is, in some ways, the opposite of the first, as it is premised on voters knowing

\footnotetext{
${ }^{13}$ We use the same formula, despite the different outcome variable, to reduce researcher degrees of freedom.
} 


\section{FIGURE 5. Selected Coefficients from a Model of Perceptions of MPs' Brexit Stances}

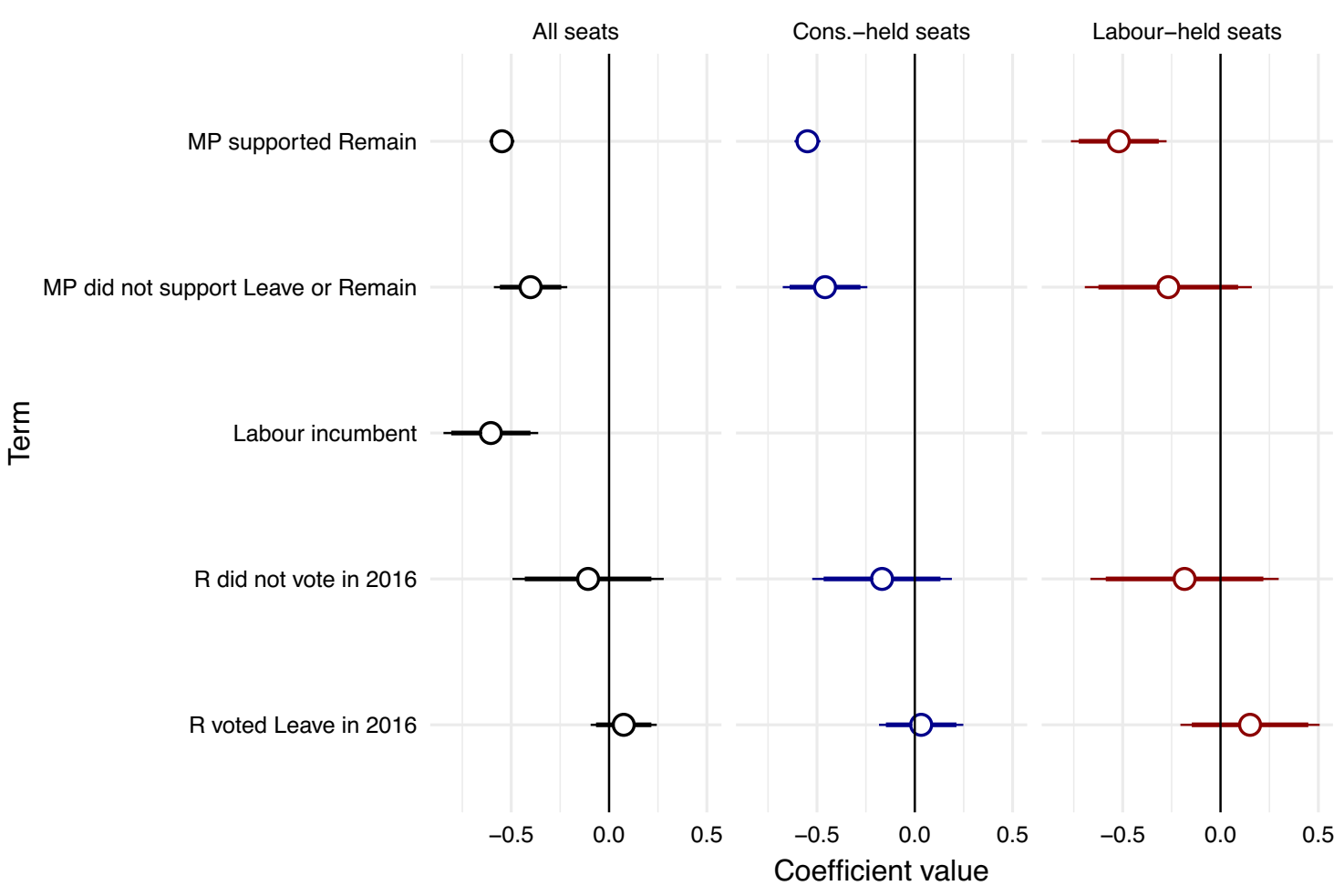

Note: Negative coefficients indicate greater perceived opposition to Brexit. Full regression models are reported in Table S6.

about MPs' positions on the issue of Europe not only currently but also in previous elections. It runs as follows: our regression models do not recover the causal effects of MPs choosing a position in the referendum, as some MPs (like John Redwood, Bill Cash, or Andrew Rosindell) were always going to campaign to leave the EU. It is reasonable to believe voters had already taken these preexisting positions into account. By failing to control for prior Euroskepticism, our models underestimate the effects of positions on Brexit specifically.

We are able to respond to this objection by using a measure of prior Euroskepticism for a limited set of Conservative MPs. Heppell (2013) assigned all Conservative MPs in the 2010-15 parliament to one of four categories in relation to Europe. Of the 238 MPs who sat in the 2010-15 parliament and are also considered here, five were described as "Europhile," 51 as "agnostic," 130 as "soft Euroskeptic," and 66 as "hard Euroskeptic."

Because these ratings are only available for a subset of Conservative MPs, using them in models of incumbent voting or perceptions of MP stance results in a decrease in sample size. We estimated models of incumbent voting on all 11,857 respondents in seats held by Conservatives for whom Heppell (2013) had assigned a rating, both including and omitting these ratings. We interacted these ratings with the respondent's own vote in the referendum. The inclusion of these additional terms does not change the effect of congruence: the posterior probability that congruence is smaller in the model with ratings is just $58 \%$ (see Table S10). Nor are perceptions of MPs' attitudes toward Brexit significantly associated with these ratings (Table S11). Our conclusions are therefore unchanged by the inclusion of measures of prior Euroskepticism.

\section{MPS' PERCEPTIONS OF ELECTORAL ACCOUNTABILITY FOR ISSUE STANCES}

Scholars of representation understand that legislators' actions must be explained with reference to legislators' beliefs and preferences and that legislators' beliefs can be more or less accurate (Mansbridge 2003, 517; Miller and Stokes 1963, 50-51). We have shown that constituents don't (meaningfully) sanction legislators with noncongruent issue positions, but do MPs know this? If MPs instead believe that constituents respond to their issue positions by sanctioning, then there are still perceived incentives for MPs to act in line with constituency preferences. Those incentives might be fragile, and the belief in meaningful accountability for issue stances would be a sort of noble myth, but we would nonetheless be able to explain observed levels of dyadic representation (Hanretty, Lauderdale, and Vivyan 2017) by referring to legislators' beliefs about constituency opinion and their preference for reelection.

We therefore surveyed MPs to elicit beliefs about the electoral penalty of being out of step with one's constituents. Specifically, we presented MPs with a series 


\section{BOX 1. Example Vignette Shown to MPs}

An estimated $62 \%$ of voters in Reading East voted to Remain in the 2016 referendum.

The sitting MP, Rob Wilson (Con.), campaigned for Remain in that referendum.

His main opponent, Matt Rodda (Lab.), supported Remain.

In the 2017 general election, Wilson won over 23,000 votes, or $42.3 \%$, compared with Rodda who won $49 \%$.

Now suppose that Wilson had campaigned for Leave instead.

How many votes would Wilson have won had he switched to support Leave? Please give your answer as a percentage.

of six vignettes that gave details on an incumbent MP, their position in the referendum campaign (Leave or Remain), and the position of their principal challenger, and we then asked MPs to estimate the vote share the incumbent would have won if they had campaigned for Remain instead of Leave (or vice versa). We supplied MPs with information on the incumbent's actual vote share in the 2017 election and estimates of Leave/ Remain support in each incumbent's constituency. One of the vignettes used is shown in Box 1; the full survey wording is reported in the Appendix.

We presented MPs with vignettes because we wished to compare MPs' beliefs with the estimates derived from regression models of voter behavior. For this we need precise quantitative estimates rather than vague quantifiers ("a great deal," "somewhat," etc.). Vignettes, because they present survey respondents with precise, relevant factual stimuli, make these precise estimates possible. We asked MPs for their views on other MPs' electoral fortunes (rather than their own) in order to minimize any potential spotlight effect that might cause MPs to overestimate the salience of their own actions to voters, but it is still possible that MPs as a group overestimate the salience of individual politicians' stances. We also presented MPs with even numbers of Leaveand Remain-supporting incumbents. Within these groups, we selected incumbents who had high, average, and low values of congruence (high $=62 \%$ of constituents supported the incumbent's position; average $=50 \%$ of constituents supported the incumbent's position; low $=38 \%$ of constituents supported the incumbent's position). We additionally selected only incumbents who faced challengers with a contrasting position on Brexit, since these contests represent the most favorable case for an accountability effect.

The survey was fielded between February 3 and March 25, 2019, by Savanta ComRes, an opinion research firm that conducts regular panel studies of MPs' opinions and fielded our questions alongside other questions in an omnibus survey. A total of 111 MPs participated in the survey. Opposition MPs were overrepresented in the sample, so we weight responses to reflect the partisan composition of the House of Commons after the 2019 general election. Because of the need to preserve respondent anonymity, the individual-level responses include information on
MPs' referendum position and party only, ${ }^{14}$ except that for some MPs their referendum position was unclear or unknown (principally because they entered parliament after the 2017 or 2019 elections). Upon inspecting the data, we found that some MPs seemed to have misunderstood the question format. Although MPs were asked to give the share of the vote the incumbent would have won had they switched, a number of MPs gave uniformly low answers (less than 10 percentage points), which suggests they understood the question to be asking about the additional share of the vote the incumbent would have won. We exclude from our analysis respondents who gave blank responses or who only gave figures lower than or equal to 10 percentage points, no matter the scenario. We are left with 576 responses from 96 respondent MPs.

Figure 6 shows estimates of the change in vote share (politicians' estimates minus the incumbent's actual vote share in 2017) as a function of the degree of congruence following the switch implied by the vignette. Points are plotted using different colors to show Leave-to-Remain and Remain-to-Leave switchers separately and using different shapes to show estimates from respondent MPs who originally supported Leave, Remain, or who had no clear position. Most estimates of change (four in every seven responses) are between -5 percentage points and +3 percentage points. The dashed gray line shows a weighted least-squares fit to the data.

Figure 6 provides a first indication that MPs do not expect that fellow MPs win substantially more votes by switching positions to become more congruent. On its own, however, the figure is not sufficient. In order to recover a figure that matches, as closely as possible, the estimates from our analysis of voter behavior, we model MPs' estimates of counterfactual vote share using a multilevel linear regression. The parameters in the model are an intercept, a dummy variable that has a value of one if the incumbent's previous position was to support Remain, and the value of congruence. These additional parameters have a substantive interpretation. The intercept allows for MPs to judge that incumbents in our vignettes generally do better or worse by switching. A negative intercept (which is suggested by Figure 6) would indicate that MPs generally think incumbents do worse by switching position regardless of whether this switch improves congruence. The dummy variable measuring the candidate's original position allows for certain switches to be regarded as generally positive or negative. A positive coefficient on this variable would, for example, indicate that switching to support Leave is regarded as electorally beneficial (perhaps because it signals independent-mindedness: Campbell et al. 2019). The lagged vote share variable accounts for an obvious determinant of election outcomes (even hypothetical ones) and is better than

\footnotetext{
${ }^{14}$ We supplied Savanta ComRes with a list of MPs and positions, and Savanta ComRes merged this data with the survey data and sent us the resulting file. MPs were not asked for their referendum positions as part of the survey.
} 
FIGURE 6. MPs Estimates of Counterfactual Vote Shares Had Named Incumbent MPs Shifted Position on Brexit

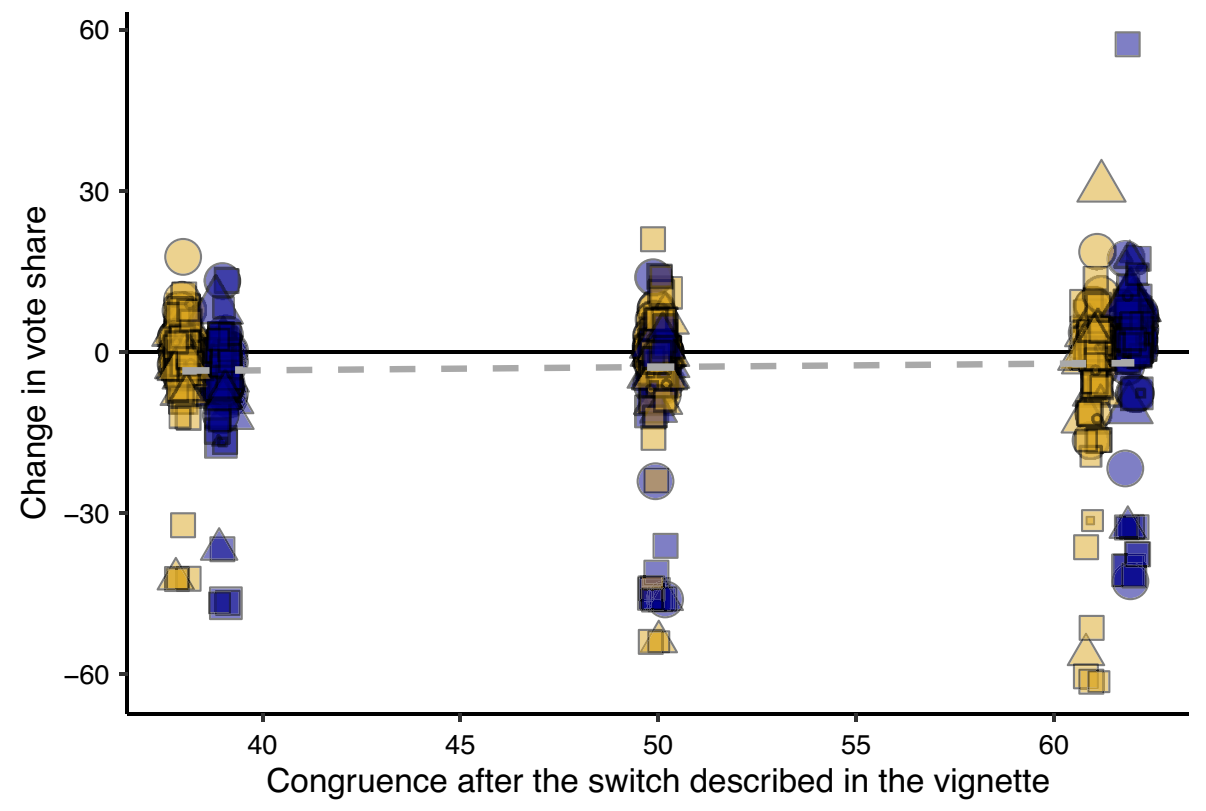

Vignette switch

Leave->Remain $\bigcirc$ Remain->Leave

Respondent position $\circ$ Leave $\square$ Remain $\Delta$ Unknown

directly modeling changes for reasons set out by Tennant et al. (2021). We also include in our model respondent-specific random intercepts, which allow for more generous and/or more variable respondent MPs.

The resulting regression model is shown in Table 1. Although our best estimate for the intercept is negative, indicating that switching of any kind brings electoral costs, the coefficient is not significantly different from zero. The coefficient on "original position Remain" is positive, indicating that MPs thought that switches to support Leave would generally have been vote-winning, independently of whether they took place in a Leavesupporting or a Remain-supporting constituency. The influence of past vote share is statistically and substantively significant. Our focus, however, is on the effect of congruence. The coefficient reports the effect of a single unit increase, and so the effect of a one-standarddeviation increase is roughly 11 times larger, at 1.5 percentage points (95\% CI: $[0.4,2.66])$. This figure is consistent with, but slightly larger than, the aggregate implications of our conditional issue sanctioning model (as above, 0.95 percentage points (95\% CI: $[0.53,1.38]$ ). Although effects at the upper end of this range (above 2 percentage points) would be regarded as substantively significant, our overall conclusion, bearing in mind the central estimate and the fact that we showed MPs the most favorable contests for issue accountability, is that MPs do, on average, believe that their accountability for issue stances is minimal.

Our claim throughout has been that the coefficient on congruence in our model of MPs' judgements can be

\section{TABLE 1. Multilevel Regression of MPs' Responses to Survey Vignettes}

\begin{tabular}{lc}
\hline & Coefficient \\
\hline Intercept & $-0.693(3.464)$ \\
Original share & $0.770(0.085)^{* * *}$ \\
Congruence & $0.140(0.052)^{* *}$ \\
Remain to Leave switch & $3.469(1.043)^{* * *}$ \\
AIC & $4,439.825$ \\
BIC & $4,465.930$ \\
Log Likelihood & $-2,213.912$ \\
Num. obs. & 573 \\
Num. respondents & 96 \\
Var: Resp. (Intercept) & 69.588 \\
Var: Residual & 108.509 \\
\hline Note: ${ }^{*} p<0.05 ;{ }^{* *} p<0.01 ;{ }^{* * *} p<0.001$. & \\
\hline
\end{tabular}

compared with our estimates of the effects of congruence from our models of voter behavior. This claim is less tenable the more MPs engage in expressive survey responses (Berinsky 2018) by estimating large vote shares for incumbents who switch to their preferred position; carry out survey satisficing (Krosnick 1999) by giving estimates of zero, one hundred, or "no change" responses; or incorporate additional vignette-specific contextual information not included in our individuallevel analysis. In supplementary analysis, we describe a set of additional models that exclude prima facie expressive or survey-satisficing responses and drop 
one vignette at a time. When expressive or surveysatisficing responses are excluded, the coefficient on congruence is smaller but never smaller than 0.1 , or $70 \%$ of the value reported in Table 1 . When individual vignettes are dropped, the coefficient on congruence varies but the differences between the baseline model and the leave-one-out models are never statistically significant. We encourage researchers who intend to elicit politicians' estimates of electoral accountability to consider these robustness checks when carrying out their analyses and to use prefatory remarks that can minimize expressive responses (Berinsky 2018, 21415). In this particular case, MPs responses are consistent with the results of our analysis of voter behavior, but that does not absolve researchers of the need to check for particular biases and processes common to all survey respondents.

\section{CONCLUSIONS}

In this study, we assessed the electoral benefit to incumbents of being in step with their constituents. To do this we estimated the effects on individual voters in the 2017 UK general election of having an MP who shared the respondent's position on the UK's exit from the EU. Averaging across all voters, we found that voters were 2.5 percentage points more likely to vote for an incumbent who shared their position on Brexit. In seats where the incumbent and the principal challenger held different positions on Brexit, this effect was greater: 4 percentage points. The aggregate consequences of these individual-level findings are smaller in magnitude because gains amongst Brexit-supporting voters are offset by losses among Brexit opponents. We estimate that a one-standard-deviation increase in congruence - understood as the percentage of constituents who share the incumbent's position - is associated with an increase in vote share of 0.6 percentage points, and that four of 632 seats might have changed parties, had incumbents adopted the vote-maximizing issue stance. In a follow-up study of MPs, we showed that MPs' estimates of the benefits on being in step are similar to the estimates we have presented here. On this basis, we conclude that MPs are not held accountable for their individual issue stances to any substantially meaningful degree.

We have made two distinctive contributions that we highlight here. The first is a methodological contribution: we have shown how vignettes can be used to elicit politicians' estimates of issue accountability, estimates that, in our particular context, were comparable in sign and magnitude to estimates based on the analysis of voter behavior. Vignettes and models of voter behavior needn't produce comparable estimates-politicians may have mistaken beliefs about electoral accountabilitybut our findings show that legislators as a group are not subject to a "spotlight effect" (Gilovich, Medvec, and Savitsky 2000) that leads them to overstate the importance of their own policy stances. Vignettes and models of voter behavior are complements rather than substitutes, and the two can be fruitfully combined. Where politicians' estimates of issue accountability are smaller than estimates from models of voter behavior, researchers can improve issue accountability (assuming this to be a good thing) by publicizing their findings about voter behavior. Where instead politicians overestimate issue accountability, researchers may instead combat a "noble myth" of highly responsive policy-aware voters.

Our second contribution lies in confirming challenger position as an important mechanism of electoral issue accountability. Incumbents are only penalized for being out of step on an issue when their principal challenger has a different position on that issue. We are not the first to make this argument (Hollibaugh, Rothenberg, and Rulison 2013), but we are the first to show this using candidates' actual issue positions rather than survey respondents' perceptions of candidates. In this respect we are aided by British electoral geography and the multiparty system, which means that candidates from the same party can face challengers with very different positions on Brexit. This finding has relevance across all systems that use single-member plurality, including studies of Congressional elections in the United States.

We have made claims about voter behavior in a particular British election. To what extent do our findings generalize across time and space? We argue that our findings represent an upper bound on the degree of individual accountability for issue positions found in British politics and that they are likely to generalize to other party-centered systems that use single-member districts. We argue that this is an upper bound on similar effects for the British case because Brexit isin absolute terms - a very important issue in British politics; because Brexit is-in relative terms - a more important issue than other issues that have prompted within-party division such as fox-hunting or abortion; and because we hold the auxiliary belief that accountability is likely to be greater on more important issues than less important issues. Our findings thus generalize across time within one country.

We also argue that our findings are likely to generalize across space to other countries that use singlemember districts, though the degree to which they generalize will be context specific. (We speak only to systems that use single-member districts because only these systems have the same one-to-one representative link). Suppose that the incentive to be in step with one's constituents on a particular issue depends on the general system-level incentive to cultivate a personal vote, and on the importance of the issue, and that the general system-level incentive to cultivate a personal vote follows the ranking set out in Carey and Shugart (1995). We can claim that individual issue accountability for issues with similar or lesser importance than Brexit will be either similar or weaker for other countries that, like the UK, use single-member plurality with party endorsements (Carey and Shugart's category [a]) - a category that includes India, Canada, and much of East Africa and the Caribbean.

For countries that have-in Carey and Shugart's (1995) typology - stronger incentives to cultivate a personal vote, our ability to generalize will depend on the 
relative contribution of issue importance and systemlevel incentives. If issue importance affects issue accountability much more than the system-level incentives, then our decision to study an extremely important issue in Brexit may allow us to make claims about issue accountability for issues of average importance in other countries with stronger system-level incentives. There are good reasons to think that issue importance matters greatly (Bovitz and Carson 2006; Highton 2019). We therefore argue that our findings provide information about the degree of accountability for issue positions, on issues of average importance, in other countries with stronger system-level incentives. For example: Carey and Shugart judge that France (because of the tworound system) and Australia (because of the alternative vote) have higher system-level incentives to cultivate a personal vote than the UK. We would argue that Brexit is more important to the UK political system than the average issue in French and Australian politics and that it is therefore reasonable to believe that issue accountability for the average issue in those countries is equal to, or less than, the issue accountability effects we show here.

Our study has normative implications for electoral system choice. Specifically, we believe our findings make single-member plurality less attractive, because it does not generate within-party incentives for one-toone congruence between the median voter within a constituency and the representative of that constituency. Within-party congruence still occurs (Hanretty, Lauderdale, and Vivyan 2017), but it presumably occurs thanks to other mechanisms such as intrinsic motivation or selection. Within-party congruence is, we argue, an important part of the defense of singlemember plurality-or put slightly differently, we do not think defenders of single-member plurality systems would be comfortable with the prospect that a Conservative MP in central London or Toronto faces the same set of policy incentives as a Conservative MP in East Anglia or Alberta. Although single-member plurality systems can be defended on other grounds, they should not be defended on the grounds that they generate particularly strong reasons for legislators to follow their constituency's policy preferences.

\section{SUPPLEMENTARY MATERIALS}

To view supplementary material for this article, please visit http://dx.doi.org/10.1017/S0003055421000514.

\section{DATA AVAILABILITY STATEMENT}

Research documentation and data that support the findings of this study are openly available at the APSR Dataverse: https://doi.org/10.7910/DVN/KSTD9J. The multilevel models shown in the article were estimated using the brms package (Bürkner 2017) for the R statistical environment ( $\mathrm{R}$ Core Team 2019). Figures were created using ggplot2 (Wickham 2016).

\section{ACKNOWLEDGMENTS}

We thank Sophie Hill, Steve Fisher, and members of the Quantitative Political Science Reading Group at Royal Holloway for helpful comments on earlier versions of this paper.

\section{FUNDING STATEMENT}

The research was funded by the Leverhulme Trust (Philip Leverhulme Prize 2018) and through the British Election Study (Economic and Social Research Council grant ES/S015671/1).

\section{CONFLICT OF INTEREST}

The authors declare no ethical issues or conflicts of interest in this research.

\section{ETHICAL STANDARDS}

The authors declare the human subjects research in this article was reviewed and approved by the ethics committee at Royal Holloway, University of London (application ID 1808). The authors affirm that this article adheres to the APSA's Principles and Guidance on Human Subject Research.

\section{REFERENCES}

Ansolabehere, Stephen, and Philip Edward Jones. 2010. "Constituents' Responses to Congressional Roll-Call Voting." American Journal of Political Science 54 (3): 583-97.

Banducci, Susan, and Jeffrey Karp. 1994. "Electoral Consequences of Scandal and Reapportionment in the 1992 House Elections." American Politics Quarterly 22 (1): 3-26.

Basinger, Scott. 2013. "Scandals and Congressional Elections in the Post-Watergate Era." Political Research Quarterly 66 (2): 385-98.

Berinsky, Adam. 2018. "Telling the Truth about Believing the Lies? Evidence for the Limited Prevalence of Expressive Survey Responding." The Journal of Politics 80 (1): 211-24.

Blais, Julie, Scott Pruysers, and Philip Chen. 2019. "Why Do They Run? The Psychological Underpinnings of Political Ambition." Canadian Journal of Political Science/Revue canadienne de science politique 52 (4): 761-79.

Bovitz, Gregory, and Jamie Carson. 2006. "Position-Taking and Electoral Accountability in the US House of Representatives." Political Research Quarterly 59 (2): 297-312.

Brambor, Thomas, William Roberts Clark, and Matt Golder. 2005. "Understanding Interaction Models: Improving Empirical Analyses." Political Analysis 14 (1): 63-82.

Breen, Richard, Kristian Bernt Karlson, and Anders Holm. 2018. "Interpreting and Understanding Logits, Probits, and Other Nonlinear Probability Models." Annual Review of Sociology 44: 39-54.

Broockman, David, and Christopher Skovron. 2018. "Bias in Perceptions of Public Opinion among Political Elites." American Political Science Review 112 (3): 542-63.

Butler, David, and Dennis Kavanagh. 1997. The British General Election of 1997. London: Palgrave.

Butler, David, and Donald Stokes. 1971. Political Change in Britain: Forces Shaping Electoral Choice. New Orleans, LA: Pelican. 
Bürkner, Paul-Christian. 2017. "brms: An R Package for Bayesian Multilevel Models Using Stan." Journal of Statistical Software 80 (1): 1-28.

Campbell, Rosie, Philip Cowley, Nick Vivyan, and Markus Wagner. 2019. "Legislator Dissent as a Valence Signal." British Journal of Political Science 49 (1): 105-28.

Canes-Wrone, Brandice, David Brady, and John Cogan. 2002. "Out of Step, Out of Office: Electoral Accountability and House Members' Voting." American Political Science Review 96 (1): 127-40.

Canes-Wrone, Brandice, William Minozzi, and Jessica Bonney Reveley. 2011. "Issue Accountability and the Mass Public." Legislative Studies Quarterly 36 (1): 5-35.

Carey, John, and Matthew Shugart. 1995. "Incentives to Cultivate a Personal Vote: A Rank Ordering of Electoral Formulas." Electoral Studies 14 (4): 417-39.

Chaffin, Joshua. 2017. "UK Election: Shock as Blue-Blooded Kensington Turns Red." Financial Times, June 10.

Chen, Serena, David Shechter, and Shelly Chaiken. 1996. "Getting at the Truth or Getting Along: Accuracy- versus ImpressionMotivated Heuristic and Systematic Processing." Journal of Personality and Social Psychology 71 (2): 262-75.

Colantone, Italo, and Piero Stanig. 2018. "Global Competition and Brexit." American Political Science Review 112 (2): 201-18.

Cowley, Philip. 2014. "Almost 70\% of People Know the Name of Their MP." British Election Study [blog]. https://www. britishelectionstudy.com/bes-findings/almost-70-of-people-knowthe-name-of-their-mp-by-professor-phil-cowley-university-ofnottingham/.

Cowley, Philip, and Dennis Kavanagh. 2018. The British General Election of 2017. New York: Springer.

Curtice, John, Stephen Fisher, and Michael Steed. 2005. "Appendix 2: The Results Analysed." In The British General Election of 2005, eds. Dennis Kavanagh and David Butler, 235-59. London: Palgrave Macmillan.

Depauw, Sam, and Shane Martin. 2009. "Legislative Party Discipline and Cohesion in Comparative Perspective." In Intra-Party Politics and Coalition Governments, eds. Daniela Giannetti and Kenneth Benoit, 103-20. London: Routledge.

Eggers, Andrew, and Alexander Fisher. 2011. "Electoral Accountability and the UK Parliamentary Expenses Scandal: Did Voters Punish Corrupt MPs?" Unpublished Working Paper.

Fieldhouse, Ed, Jane Green, Geoff Evans, Hermann Schmitt, Cees van der Eijk, Jon Mellon, and Chris Prosser. 2018. British Election Study Internet Panel waves 1-14 [data collection]. https:// www.britishelectionstudy.com/.

Fortunato, David, and Nathan Monroe. 2018. "Agenda Control and Electoral Success in the US House." British Journal of Political Science 50 (4): 1583-92.

Gilovich, Thomas, Victoria Husted Medvec, and Kenneth Savitsky. 2000. "The Spotlight Effect in Social Judgment: An Egocentric Bias in Estimates of the Salience of One's Own Actions and Appearance." Journal of Personality and Social Psychology 78 (2): 211-22.

Golder, Matt, and Jacek Stramski. 2010. "Ideological Congruence and Electoral Institutions." American Journal of Political Science 54 (1): 90-106.

Green, Jane, and Sara Hobolt. 2008. "Owning the Issue Agenda: Party Strategies and Vote Choices in British Elections." Electoral Studies 27 (3): 460-76.

Griffin, John. 2006. "Electoral Competition and Democratic Responsiveness: A Defense of the Marginality Hypothesis." Journal of Politics 68 (4): 911-21.

Griffin, John, and Patrick Flavin. 2007. "Racial Differences in Information, Expectations, and Accountability." Journal of Politics 69 (1): 220-36.

Hanretty, Chris. 2017. “Areal Interpolation and the UK's Referendum on EU Membership." Journal of Elections, Public Opinion and Parties 27 (4): 1-18.

Hanretty, Chris, Jonathan Mellon, and Patrick English. 2021. "Replication Data for: Members of Parliament are Minimally Accountable for Their Issue Stances (and They Know It)." Harvard Dataverse. Dataset. https://doi.org/10.7910/DVN/KSTD9J.

Hanretty, Chris, Benjamin Lauderdale, and Nick Vivyan. 2017. "Dyadic Representation in a Westminster System." Legislative Studies Quarterly 42 (2): 235-67.
Hanretty, Chris, Benjamin Lauderdale, and Nick Vivyan. 2018. "Comparing Strategies for Estimating Constituency Opinion from National Survey Samples." Political Science Research and Methods 6 (3): 571-91.

Hansard Society. 2013. Audit of Political Engagement 10. London: The Hansard Society.

Heath, Oliver, and Matthew Goodwin. 2017. "The 2017 General Election, Brexit and the Return to Two-Party Politics: An Aggregate-Level Analysis of the Result." Political Quarterly 88 (3): $345-58$

Heppell, Timothy. 2013. "Cameron and Liberal Conservatism: Attitudes within the Parliamentary Conservative Party and Conservative Ministers." British Journal of Politics \& International Relations 15 (3): 340-61.

Heppell, Timothy, Andrew Crines, and David Jeffery. 2017. "The United Kingdom Referendum on European Union Membership: The Voting of Conservative Parliamentarians." Journal of Common Market Studies 55 (4): 762-78.

Highton, Benjamin. 2019. "Issue Accountability in US House Elections." Political Behavior 41 (2): 349-67.

Hollibaugh, Gary, Lawrence Rothenberg, and Kristin Rulison. 2013. "Does It Really Hurt to Be Out of Step?" Political Research Quarterly 66 (4): 856-67.

Honaker, James, Gary King, and Matthew Blackwell. 2011. "Amelia II: A Program for Missing Data." Journal of Statistical Software 45 (7): $1-47$.

Iacus, Stefano, Gary King, and Giuseppe Porro. 2012. "Causal Inference without Balance Checking: Coarsened Exact Matching." Political Analysis 20 (1): 1-24.

Jacobson, Gary. 1996. "The 1994 House Elections in Perspective." Political Science Quarterly 111 (2): 203-23.

Johns, Robert. 2010. "Measuring Issue Salience in British Elections: Competing Interpretations of 'Most Important Issue."” Political Research Quarterly 63 (1): 143-58.

Kam, Christopher. 2009. Party Discipline and Parliamentary Politics. Cambridge: Cambridge University Press.

King, Gary, and Andrew Gelman. 1991. "Systemic Consequences of Incumbency Advantage in U.S. House Elections." American Journal of Political Science 35 (1): 110-38.

King, Anthony, and David Butler. 1966. The British General Election of 1966. London: Macmillan.

Krosnick, Jon. 1999. "Survey Research." Annual Review of Psychology 50 (1): 537-67.

Lee, David. 2008. "Randomized Experiments from Non-Random Selection in US House Elections." Journal of Econometrics 142 (2) 675-97.

Lloren, Anouk, and Reto Wüest. 2016. "Are Opinion Leaders Better Represented?" West European Politics 39 (4): 800-34.

Mansbridge, Jane. 2003. "Rethinking Representation." American Political Science Review 97 (4): 515-28.

Martin, Shane. 2016. "Policy, Office and Votes: The Electoral Value of Ministerial Office." British Journal of Political Science 46 (2): 281-96.

Mellon, Jonathan, Geoffrey Evans, Edward Fieldhouse, Jane Green, and Christopher Prosser. 2018. "Brexit or Corbyn? Campaign and Inter-Election Vote Switching in the 2017 UK General Election." Parliamentary Affairs 71 (4): 719-37.

Miller, Warren, and Donald Stokes. 1963. "Constituency Influence in Congress." American Political Science Review 57 (1): 45-56.

Norton, Philip. 2003. "Cohesion without Discipline: Party Voting in the House of Lords." Journal of Legislative Studies 9 (4): 57-72.

Nyhan, Brendan, Eric McGhee, John Sides, Seth Masket, and Steven Greene. 2012. "One Vote Out of Step? The Effects of Salient Roll Call Votes in the 2010 Election." American Politics Research 40 (5): 844-79.

Pattie, Charles, Edward Fieldhouse, and Ron Johnston. 1994. "The Price of Conscience: The Electoral Correlates and Consequences of Free Votes and Rebellions in the British House of Commons, 1987-92." British Journal of Political Science 24 (3): 359-80.

Pereira, Miguel. 2020. "Understanding and Reducing Biases in Elite Beliefs about the Electorate.” PhD Diss. Washington University in St Louis.

Portmann, Marco, David, Stadelmann, and Reiner, Eichenberger. 2012. "District Magnitude and Representation of the Majority's 
Preferences: Evidence from Popular and Parliamentary Votes." Public Choice 151(3-4): 585-610.

R Core Team. 2019. R: A Language and Environment for Statistical Computing. Vienna: R Foundation for Statistical Computing.

Rogers, Steven. 2017. "Electoral Accountability for State Legislative Roll-Calls and Ideological Representation." American Political Science Review 111 (3): 555-71.

Shipman, Tim. 2016. All Out War: The Full Story of How Brexit Sank Britain's Political Class. New York: HarperCollins.

Skovron, Christopher. 2018. "What Politicians Believe about Electoral Accountability." SSRN Working Paper 3309906.

Smith, Timothy Hallam. 2013. "Are You Sitting Comfortably? Estimating Incumbency Advantage in the UK: 1983-2010.” Electoral Studies 32 (1): 167-73.
Sulkin, Tracy, Paul Testa, and Kaye Usry. 2015. "What Gets Rewarded? Legislative Activity and Constituency Approval.” Political Research Quarterly 68 (4): 690-702.

Tennant, Peter W. G., Kellyn F. Arnold, George T. H. Ellison, and Mark S. Gilthorpe. 2021. “Analyses of 'Change Scores' Do Not Estimate Causal Effects in Observational Data." International Journal of Epidemiology https://doi.org/10.1093/ije/dyab050.

Vivyan, Nick, and Markus Wagner. 2012. "Do Voters Reward Rebellion? The Electoral Accountability of MPs in Britain." European Journal of Political Research 51 (2): 235-64.

Wickham, Hadley. 2016. ggplot2: Elegant Graphics for Data Analysis. New York: Springer-Verlag.

Wilson, Matthew, and Paul Gronke. 2000. "Concordance and Projection in Citizen Perceptions of Congressional Roll-Call Voting." Legislative Studies Quarterly 25 (3): 445-67. 